\title{
Developmental Expression of Retinal Cone cGMP-Gated Channels: Evidence for Rapid Turnover and Trophic Regulation
}

\author{
Gladys Y.-P. Ko, Michael L. Ko, and Stuart E. Dryer \\ Department of Biology and Biochemistry, University of Houston, Houston, Texas 77204-5513
}

The cyclic GMP-gated cationic channels of vertebrate photoreceptors are essential for visual phototransduction. We have examined the developmental regulation of cGMP-gated channels in morphologically identified cones in the chick retina. Expression of cone-type cGMP-gated channel mRNA can be detected at embryonic day 6 (E6), but expression of functional channels, as accessed by patch-clamp recordings, cannot be detected until E8. Plasma membrane channels in embryonic cones have a high turnover rate because inhibition of protein synthesis or disruption of the Golgi apparatus causes an almost complete loss of functional cGMP-gated channels within $12 \mathrm{hr}$. Different subpopulations of cones begin to express functional channels at different developmental stages, but all cones express channels by E10. Expression of cGMP-gated channels in at least one cone subpopulation appears to require one or more soluble differentiation factors, which are presumably present in

The cGMP-gated cationic channels of photoreceptors are essential elements of vertebrate phototransduction cascades (for review, see Stryer, 1986; Molday and Molday, 1998). Considerable progress has been made toward understanding the molecular aspects of gating (Liu et al., 1996, 1998; Ruiz and Karpen, 1997; Matulef et al., 1999; Paoletti et al., 1999; Shammat and Gordon, 1999), permeation (Goulding et al., 1993; Root and MacKinnon, 1993, 1994; Dzeja et al., 1999; Seifert et al., 1999), and modulation (Gordon et al., 1992; Hsu and Molday, 1993; Molokanova et al., 1997, 1999a,b, 2000; Grunwald et al., 1998; Weitz et al., 1998) of these channels. In contrast, little is known about regulation of the developmental expression of these channels in photoreceptor plasma membranes. This is an important question, because reduced plasma membrane expression of these channels leads to photoreceptor degeneration in rodents (LeConte and Barnstable, 2000) and humans (Dryja et al., 1995).

In developing rat rods, the expression of cGMP-gated channel $\alpha$-subunit transcripts can be detected by the time of birth (Ahmad et al., 1990). Immunochemically detectable rod-type cGMP-gated channel $\alpha$-subunits are not initially detected until the seventh postnatal day and increase thereafter (Chiang and Barnstable, 1998). The expression of cGMP-gated channel proteins in rats coincides with the expression of several other rod outer segment proteins, including opsins (Treisman et al.,

\footnotetext{
Received July 17, 2000; revised Sept. 14, 2000; accepted Oct. 12, 2000.

This work was supported by National Institutes of Health Grant EY-11973.

Correspondence should be addressed to Dr. Stuart Dryer, Department of Biology and Biochemistry, University of Houston, Houston, TX 77204-5513. E-mail: SDryer@uh.edu.

Copyright (C) 2001 Society for Neuroscience $\quad 0270-6474 / 01 / 210221-09 \$ 15.00 / 0$
}

the normal microenvironment of the developing retina. Application of chick embryo extract (CEE), a rich source of trophic factors, causes marked stimulation of cGMP-gated channel expression in chick cones at E8, but not at E6. Inhibition of MAP kinase (Erk) signaling using PD98059, or inhibition of PI3 kinase signaling by LY294002, blocked the stimulatory effects of CEE on E8 cones. Several recombinant trophic factors were also tested, but none could mimic the stimulatory effects of CEE on channel expression. In summary, the developmental expression of cGMP-gated cationic channels in embryonic cones appears to be regulated by epigenetic factors. The ability of cones to respond to these epigenetic factors is also developmentally regulated.

Key words: CNG channels; photoreceptor; cone; retina; development; chick embryo

1988; He et al., 1998), arrestins (Ni et al., 1992), and cGMP phosphodiesterase (He et al., 1998). However, the stages at which functional cGMP-gated channels are expressed in photoreceptor plasma membranes has not been determined in any species or cell type, and it is not known whether the normal expression of these channels is regulated by inductive cell-cell interactions or trophic factors.

The differentiation of photoreceptors has been extensively studied in embryonic chicks (for review, see Adler, 1993), and these cells are well suited for studies of neuronal differentiation. A significant technical advantage of the chick is that at least one class of photoreceptor, the cones, can be readily identified in dissociated retinal cell cultures on the basis of morphological criteria in unstained cells. Postmitotic cells in the vertebrate retina can differentiate into several different cell types, but several lines of evidence suggest that photoreceptors represent the "default" pathway for differentiation of postmitotic chick retinal cells (Adler, 1986; Adler and Hatlee, 1989; Repka and Adler, 1992; Belecky-Adams et al., 1996). The fate of developing chick retinal cells can be influenced by application of various trophic factors, including CNTF (Fuhrmann et al., 1995, 1998a), BDNF (Das et al., 1997; Frade et al., 1997), and bFGF (Hicks and Courtois, 1992; Lillien and Cepko, 1992), which are endogenously expressed in the chick retina.

The purpose of the present study was to determine the developmental stages at which functional cGMP-gated cationic channels are first detectable in morphologically identifiable embryonic chick cone photoreceptors, to determine whether this developmental time course is regulated by trophic factors, and to provide information as to the turnover rate of plasma membrane channels. 

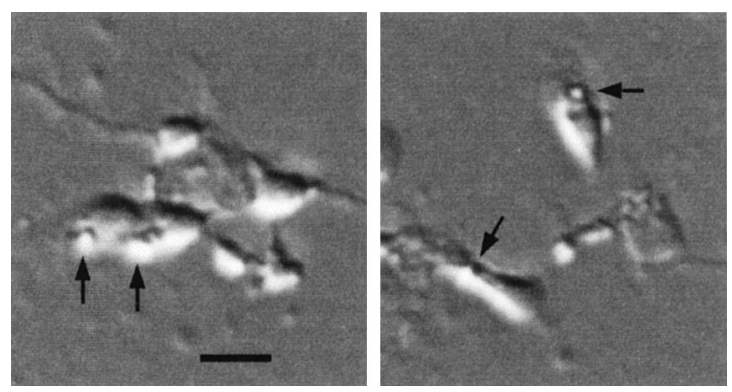

Figure 1. Two different Hoffman optics photomicrographs of embryonic chick cones isolated at E6 and maintained in culture for $5 \mathrm{~d}$. Arrows indicate oil droplets, the principle criterion for identification of this cell type in dissociated cell culture. Scale bar, $10 \mu \mathrm{m}$.

\section{MATERIALS AND METHODS}

Cell isolation and culture. Chick retinas were dissociated at different embryonic stages from embryonic day 6 (E6) to E10, essentially as described by Adler and Hatlee (1989). Briefly, retinas were dissected and incubated in a solution comprised of (in $\mathrm{mm}$ ): $123 \mathrm{NaCl}, 5.36 \mathrm{KCl}, 9.51$ $\mathrm{Na}_{2} \mathrm{HPO}_{4}$, and $1.48 \mathrm{NaH}_{2} \mathrm{PO}_{4}$, with $0.1 \mathrm{gm} / \mathrm{ml}$ glucose and $0.5 \mathrm{mg} / \mathrm{ml}$ trypsin at $37^{\circ} \mathrm{C}$ for $25 \mathrm{~min}$ and then dissociated by trituration using a fire-polished Pasteur pipette. Retinal cells were grown on glass coverslips coated with poly-D-lysine (molecular weight 276,000 ) and maintained in a $5 \% \mathrm{CO}_{2}$ incubator at $39^{\circ} \mathrm{C}$ in the dark for various lengths of time in a medium consisting of Eagle's minimal essential medium (Biowhittaker, Walkersville, MD) supplemented with $10 \%$ heat-inactivated horse serum (Biowhittaker), $2 \mathrm{~mm}$ glutamine, $50 \mathrm{U} / \mathrm{ml}$ penicillin, and $50 \mu \mathrm{g} / \mathrm{ml}$ streptomycin. In most experiments, the medium also contained $20 \mathrm{ng} / \mathrm{ml}$ recombinant rat ciliary neurotrophic factor (CNTF). In some experiments, E10 chick embryo extract (CEE), heat-inactivated CEE, various drugs, and/or recombinant trophic factors were added to culture media at concentrations indicated in the text. To obtain CEE, an E10 chick embryo was passed through a $10 \mathrm{ml}$ syringe into a centrifuge tube containing $3 \mathrm{ml}$ of Earle's balanced salts solution (Sigma, St. Louis, MO). This extract was kept at $4^{\circ} \mathrm{C}$ for $2 \mathrm{hr}$ and then centrifuged at 15,000 rpm for $1.5 \mathrm{hr}$. The supernatant (CEE) was stored at $4^{\circ} \mathrm{C}$ for $1-2$ weeks. CEE was heat-inactivated by incubation at $90^{\circ} \mathrm{C}$ for $30 \mathrm{~min}$. All recombinant trophic factors (CNTF, TGF $\beta-1$, BDNF, IGF-1, basic FGF, GDNF, and $\beta$-neuregulin) were obtained from R \& D Systems (Minneapolis, MN). Anisomysin, LY294002 and brefeldin-A were obtained from Calbiochem (La Jolla, CA). All other chemicals, including PD98059, were from Sigma. These drugs were applied to cultured cells for the durations indicated in the text. It bears noting that these drugs were not present in the bath salines used for patch-clamp recording. Moreover, in separate control experiments we observed that acutely applying these drugs in bath salines during patch-clamp recording had no effect on responses of patches to cGMP (data not shown), indicating that these drugs do not produce direct effects on the channels (i.e., they are not channel pore blockers or gating modifiers).

Electrophysiology. Recordings were made from cells containing one or more prominent oil droplets in the soma (Fig. 1). This morphological feature is a hallmark of cones and can be easily observed in living cells in dissociated preparations. A substantial number of these cells were obtained in all culture conditions, but especially in cells dissociated at E6, as noted by others (Adler and Hatlee, 1989; Gleason et al., 1992). Oil droplet-containing cells can be observed in cultures of E6 retina as soon as they adhere to the substrate. At that time, the cell bodies are somewhat rounded. After 2-3 d in culture, the cell bodies of oil droplet-containing cells become more elongated, and small neuritic expansions, possibly representing truncated outer segments, can be observed in many cells under Hoffman optics (Adler and Hatlee, 1989). Methods for inside-out patch recordings of cGMP-gated channels have been described elsewhere (Dryer and Henderson, 1991, 1993). Briefly, inside-out patches were excised into a divalent cation-free bath saline (in mM: $145 \mathrm{NaCl}, 10$ Na-HEPES, 1 EGTA, and 10 glucose, pH 7.4) and held at $-65 \mathrm{mV}$. Pipette solution was the same as the bath saline. Recordings were performed at room temperature $\left(22-23^{\circ} \mathrm{C}\right)$. Only one patch was excised from any given cell, and all electrodes had a resistance of $5 \mathrm{M} \Omega$. Channels were activated by gravity-fed application of varying concentrations of cGMP in bath saline. Data were stored on magnetic tape in FM mode before off-line digitization at $20 \mathrm{kHz}$ (Axoscope; Axon Instruments, Foster City, CA) and analysis (Fetchan; Axon Instruments). Concentration-response curves were fitted with the Hill equation $I_{\mathrm{s}}=$ $I_{\text {Max }}\left[S /\left(K_{\mathrm{D}}+S\right)\right]^{n}$ where $S$ is the concentration of cGMP, $K_{\mathrm{D}}$ is the dissociation constant, and $n$ is the Hill coefficient. Curve fitting of concentration-response curves was performed using a Levenburg-Marquardt least-squares routine (Origin version 6.0; Microcal, Northhampton, MA). In most of the experiments, channels were activated by bath perfusion of $100 \mu \mathrm{M}$ cGMP, which causes maximum activation of cGMPgated channels in retinal photoreceptors maintained under these conditions. In a series of pilot experiments, we determined that average capacitance of excised inside-out patches, a measure of membrane surface area, did not vary as a function of the developmental stage or culture conditions of the cones from which patches were excised. Therefore, maximum response amplitudes provide a good estimate of channel density under the conditions used in these studies, and additional normalization procedures were not performed systematically. All statistical analyses were performed using Statistica software (Statsoft, Tulsa, OK) and consisted of the Kruskal-Wallis ANOVA-by-ranks test (when comparisons were made between multiple groups), and the KolmogorovSmirnov one-sample test for deviation from a normal distribution. The Kruskal-Wallis is a nonparametric version of the standard one-way ANOVA and was used because most of the data sets described below contain groups in which the data showed significant departures from a normal distribution (Siegel and Castellan, 1988). These data sets were also analyzed by standard one-way ANOVA, which in all cases resulted in the same conclusions. Throughout, $p<0.05$ was regarded as significant. All data sets were based on recordings from between 9 and 40 inside-out patches per group.

Developmental regulation of retinal cGMP-gated cationic channel transcripts. Retinas were collected from E6, E9, E13, and E18 embryos and chicks $2 \mathrm{~d}$ after hatching, and total RNA was isolated using a commercially available version of the guanidine isothiocyanate method (Genosys, Woodlands, TX). Ten micrograms of total RNA from each age group was used to quantify expression of cGMP-gated cationic channel mRNA by RNase protection assay (RPA) using radiolabeled riboprobes. The probe for cone cGMP-gated channel transcripts consisted of a $284 \mathrm{bp}$ fragment obtained by RT-PCR (RT-PCR Select; Stratagene, La Jolla, CA) using the following matched primers: 5'-TCG-CTA-CCA-TTG-TCG-GTA-ACG-3' (forward) and 5'-CGC-AAT-CCT-GGA-ATA-TAC-GCAC-3' (reverse). These primers were designed based on sequences reported by Bonigk et al. (1993) and amplify a region with no sequence conservation between rod and cone-type channels. The probe for chicken $\beta$-actin consisted of a $68 \mathrm{bp}$ fragment obtained by RT-PCR using the following matched primers: $5^{\prime}$ TGC-TGT-GTT-CCC-ATC-TAT-CGTG-3' and 5'-TCT-TTC-TGGCCC-ATA-CCA-ACC- $3^{\prime}$. Products of the expected size were cloned into a TA vector (pCR II; Invitrogen, San Diego, CA) and sequenced. RPA probes were synthesized using a Stratagene RNA transcription kit (catalog \#200340) using ${ }^{32}$ P[UTP] (DuPont NEN, Boston, MA), and RPA was performed using Hybspeed kits (Ambion, Austin, TX) according to the manufacturer's directions. Briefly, total RNA from each age group and radiolabeled riboprobes were coprecipitated and allowed to hybridize, and nonhybridized RNA was digested with RNase. Double-stranded probe/ mRNA hybrids were precipitated, separated on denaturing polyacrylamide gels $(5.7 \%$ acrylamide, $7 \mathrm{M}$ urea, $1 \times$ Tris-Borate-EDTA), and signal was quantified by autoradiography on $\mathrm{x}$-ray film followed by densitometric analysis (Scion Image, Bethesda, MD). Data are expressed as the ratio of cone cGMP-gated channel signal to $\beta$-actin loading control. In addition, channel transcripts were determined at the same developmental stages by RT-PCR. For these experiments, a constant amount of total RNA from each stage was reverse-transcribed using random primers, amplified for 25 cycles using the primers described above, and products were separated on $1.5 \%$ agarose gels containing ethidium bromide. In addition, a sample of posthatch RNA was subjected to PCR without previous reverse transcription ( $\mathrm{RT}^{-}$control). Results of RT-PCR were in qualitative agreement with results of RPA.

\section{RESULTS}

Normal developmental expression of cone-type cGMPgated channels in chick retina

Expression of cGMP-gated cationic channel mRNA was determined from total retinal RNA isolated at various stages of embryonic development. Low but detectable levels of channel transcripts were detected as early as E6 by both RT-PCR (Fig. 2A) 

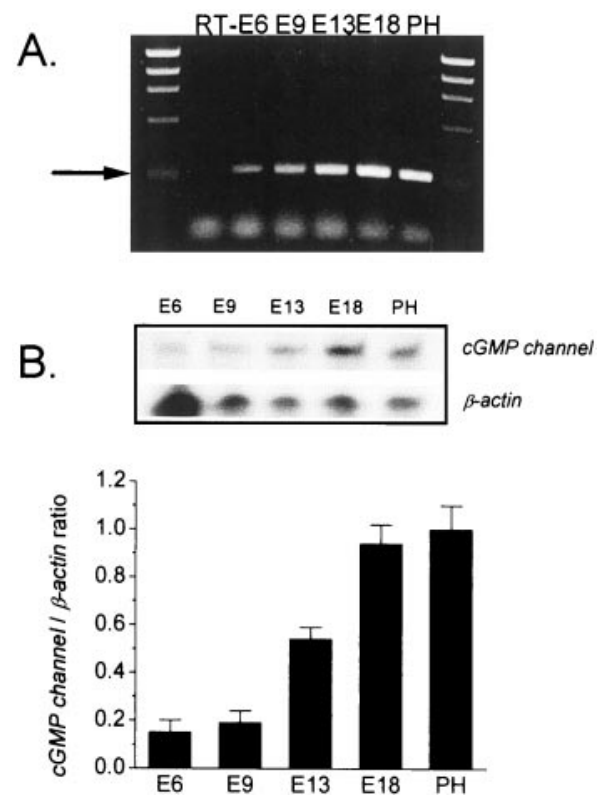

Figure 2. Developmental expression of cone-type cGMP-activated channel mRNA in embryonic chick retina. $A$, Detection of cGMP-activated channel transcripts by RT-PCR. Total RNA was isolated at the indicated developmental stages, a constant amount was reverse-transcribed, and channel cDNA was amplified using matched primers designed to obtain a 284 bp product (arrow). No product was obtained in the negative control lane in which the reverse transcription step was omitted $(R T-)$. Other developmental stages are indicated above the lanes, and $P H$ indicates $2 \mathrm{~d}$ after hatching. $B$, Quantitative analysis of developmental expression of channel transcripts by RNase protection assay. Top panel shows representative data showing signal obtained for channel transcripts, or $\beta$-actin loading controls, as indicated. Bottom panel summarizes data obtained from three replications of this experiment. The ordinate is the relative mean channel $/ \beta$-actin transcript ratios, and error bars represent SEM. Both methods indicate that cone-type cGMP-gated channel transcripts are present as early as E6 and increase during embryonic development.

and RNase protection assay (Fig. 2B). The RNase protection assays, which are more quantitative, also indicate that levels of these transcripts increase relative to $\beta$-actin loading controls until after hatching (Fig. 2B). It bears noting that Ahmad et al. (1990) and Chiang and Barnstable (1998) were able to detect cGMPgated channel transcripts several days before appearance of channel proteins in the developing rat retina. To determine whether a similar pattern is observed in chick retina, the time course of the expression of functional plasma membrane cationic channels was determined by recording the amplitudes of currents evoked by cGMP in excised inside-out patches. Excised patches were held at $-65 \mathrm{mV}$, and recordings were made in the absence of divalent cations in the bath or electrode (Dryer and Henderson, 1991). In these experiments, chick retinal cells were dissociated at various stages of embryonic development and cultured overnight in the dark, which was necessary to allow cells to adhere to the substrate sufficiently to excise patches. Recordings were made only from cells containing cell bodies with detectable oil droplets (Fig. 1). We have observed that these cells can be stained with peanut lectin, a marker for cones (data not shown), an observation consistent with previous reports (Adler et al., 1984; Blanks and Johnson, 1984; Gleason et al., 1992). In addition, Gleason et al. (1992) noted that oil droplet-containing embryonic chick retinal cells cultured under similar conditions have ultrastructural features diagnostic of cones. Patches from cells isolated at E10 and cultured overnight $(\mathrm{E} 10+1$ cells $)$ typically contained multiple
(7-12) cGMP-gated channels based on maximal responses to high concentrations $(100 \mu \mathrm{M})$ of cGMP (Fig. $3 A)$. Channel activation was dose-dependent, with a mean $K_{\mathrm{D}}$ of $40 \mu \mathrm{M}$ and a mean Hill slope of 1.95 (Fig. $3 B$ ), consistent with previous studies of cloned chicken cone-type cGMP-gated channel $\alpha$-subunits in heterologous expression systems (Bonigk et al., 1993). In contrast, significantly $(p<0.05)$ lower maximum currents were evoked in patches excised from E8 +1 cells compared with patches from E10 + 1 cells (Kruskal-Wallis test) (Fig. 3C). Moreover, cGMPgated channels could not be detected in the vast majority of E6 + 1 cells, although cells at that stage contain oil droplets, and channel transcripts are present in retina at that stage. These data suggest that expression of cone cGMP-gated channel transcripts in chicks precedes expression of functional plasma membrane cationic channels, as observed previously for rat rod-type channels (Ahmad et al., 1990; Chiang and Barnstable, 1998). However, examination of mean and SEM alone does not reveal the entire developmental pattern; it bears noting that the distribution of response amplitudes exhibits qualitative differences with the developmental stage. Thus, in E6 +1 cells and E10 +1 cells, the distribution of response amplitudes was not significantly different from a normal distribution (Kolmogorov-Smirnov one-sample test). Specifically, almost none of the patches excised from E6 + 1 cells contained functional channels, whereas nearly all patches from E10 +1 cells contained many functional channels. In contrast, the distribution of response amplitudes in patches from $\mathrm{E} 8+1$ cells is significantly different from a normal distribution $(p<0.05$; Kolmogorov-Smirnov test) and appears distinctly bimodal (Fig. 3D). At this stage, the number of cones that express many channels or that fail to express functional channels was approximately equal. These distributions raise the possibility that different subpopulations of cones acquire a substantial density of cGMP-gated channels at different developmental stages (as opposed to a more gradual acquisition of channels occurring at a uniform rate in all cone cells). Alternatively, one could also explain these data by differential cell death of cone photoreceptors, i.e., those cones that fail to express substantial densities of cGMP-gated channels could die between E8 and E10. However, recent studies indicate that chick photoreceptors do not undergo cell death (apoptotic or otherwise) between E4 and the second day after hatching (Cook et al., 1998), although other retinal cell types do undergo apoptotic cell death (Frade et al., 1997; Cook et al., 1998; Diaz et al., 2000). Therefore, differential survival of subpopulations of cones cannot explain the data on the time course of cGMP expression.

\section{Regulation of cGMP-gated channel expression in cone photoreceptors developing in vitro and evidence for trophic control}

The results described above indicate that there is an increase in the expression of functional cGMP-gated cationic channels between E6 and E10 in chick cone photoreceptors. This time course could reflect a developmental program that is intrinsic to the cells. Alternatively, normal developmental expression of these channels could depend on some type of trophic control mechanism, at least in some cells. To examine this issue, retinal photoreceptors were allowed to develop for various lengths of time in vitro, and the density of cGMP-gated channels was compared with age-matched control photoreceptors that developed primarily in ovo (Fig. 4). In this experiment, cells were isolated at E6, and patch-clamp recordings were made on the next day $(\mathrm{E} 6+1$ cells $)$ or after $3 \mathrm{~d}(\mathrm{E} 6+3$ cells $)$ or $5 \mathrm{~d}(\mathrm{E} 6+5$ cells $)$ in dissociated cell 
A.

Figure 3. Developmental expression of functional cGMPgated channels in developing cones of embryonic chick retina. $A$, Typical currents evoked by bath application of various concentrations cGMP to an excised inside-out patch from an E10 cone. Fully closed states are indicated by dotted line, and cGMP concentrations are indicated to the right of each trace. Note presence of multiple cGMP-gated channels in this patch and increasing response amplitude with concentration. $B$, Concentration-response curve constructed from a different E10 inside-out patch. Data points are shown with superimposed least-squares fit to the Hill equation, with $K_{\mathrm{D}}$ and Hill slope as indicated. $C$, Mean currents evoked by bath application of $100 \mu \mathrm{M}$ cGMP to inside-out patches excised from cone photoreceptors at the developmental stages indicated. No current was detected in the vast majority of patches excised from E6 cells. The mean current levels at E8 and E10 are significantly ( $p<$ 0.05 ) different from each other and from E6 (KruskalWallis test). $D$, Distribution of current amplitudes from data shown in $C$. Data obtained at E6 and E10 are not significantly different from a normal distribution. In contrast, data obtained at E8 are significantly $(p<0.05)$ different from a normal distribution (Kolmogorov-Smirnov one-sample test) and appear to be bimodal, suggesting existence of multiple cell populations.
B.

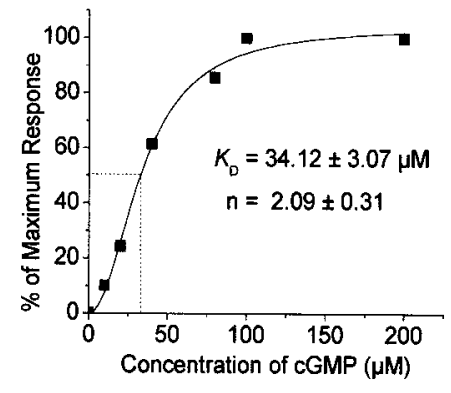

D.

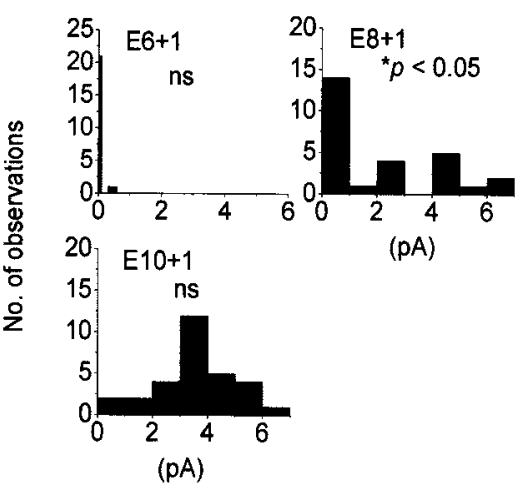

culture in the dark. Age-matched controls consisted of E8 +1 cells and E10 +1 cells, which developed primarily in ovo. Channel density was then determined by measuring mean current amplitude evoked by bath application of $100 \mu \mathrm{M}$ cGMP to excised patches. As noted above, the majority of patches from E6 +1 cells did not contain detectable cGMP-gated channels. In contrast, we observed that substantially more E6 + 3 cells expressed functional cGMP-gated channels and that the resulting mean current and the distribution of current amplitudes was similar to that observed in patches from E8 +1 cells. Specifically, there was a significantly non-normal ( $p<0.05$; Kolmogorov-Smirnov test) and apparently bimodal distribution of response amplitudes, such that only a subpopulation of patches from E6 +3 cells contained functional channels (data not shown). From this we conclude that at least one population of photoreceptors can express functional cGMP-gated channels under these culture conditions, probably the same population that normally express these channels by E8. However, this conclusion cannot be extended to all cells with photoreceptor morphology. Thus, E6 +5 cells showed the same pattern as E6 + 3 cells, i.e., a subpopulation of patches contained functional cGMP-gated channels but the overall distribution was significantly $(p<0.05)$ non-normal and apparently bimodal (Fig. $3 B)$. Moreover, the response amplitudes in this group were significantly ( $p<0.05$; Kruskal-Wallis test) less than those observed in the age-matched E10 +1 group (Fig. 4A), which exhibited a distribution of response amplitudes not significantly different from a unimodal normal distribution (Fig. 4B). This pattern was observed regardless of whether cells were cultured at either low or high cell density (data not shown). In other words, these data suggest the existence of a second population of cones for which expression of functional channels requires some sort of epigenetic factor not present in these culture conditions.

To test this hypothesis more directly, a similar experiment was performed on retinal cells cultured in medium supplemented with
$10 \% \mathrm{CEE}$, a rich source of trophic factors. Control cells were cultured in the absence of CEE or in the presence of heatinactivated CEE (Fig. 5). CEE did not have a noticeable effect on cone survival or cone morphology. However, we observed that CEE could increase the mean density of functional cGMP-gated cationic channels in patches excised from cones, but that this effect depended on the stage at which retinal cells were isolated. Thus, $10 \%$ CEE had no effect on mean current evoked by $100 \mu \mathrm{M}$ cGMP in E6 + 5 photoreceptors, which had response amplitudes similar to those observed in cells cultured in the absence of CEE or cells cultured in heat-inactivated CEE (Fig. 5A). The resulting distribution of current amplitudes was non-normal and bimodal in all three groups. This pattern was also observed in E6 + 3 cells (data not shown). In contrast, 10\% CEE caused a robust and significant $(p<0.05)$ stimulation of cGMP-gated current in cells isolated at E8, indeed this effect could be observed after just $12 \mathrm{hr}$ of culture (Fig. 5B). CEE treatment of E8 cells resulted in mean currents in excised patches comparable with those of patches from $\mathrm{E} 10+1$ cells and with an apparently unimodal distribution not significantly different from normal. An identical effect could be observed with 5\% CEE (data not shown). Heat-inactivated CEE did not produce significant stimulation of channel expression, and the amplitude and distribution of currents in patches from those cells were similar to those observed in cells cultured without a medium supplement. These data are consistent with a model in which optimal expression of functional cGMP-gated channels in at least a subpopulation of cone photoreceptors requires trophic support, but that either the emergence of these cells, or the ability of this population of cells to respond to trophic factors, is developmentally regulated and dependent on the normal microenvironment of the retina.

Are the stimulatory effects of CEE associated with synthesis of new channel molecules? To test this, E8 cells were cultured for 12 $\mathrm{hr}$ in the presence of CEE, in the presence of CEE plus the 

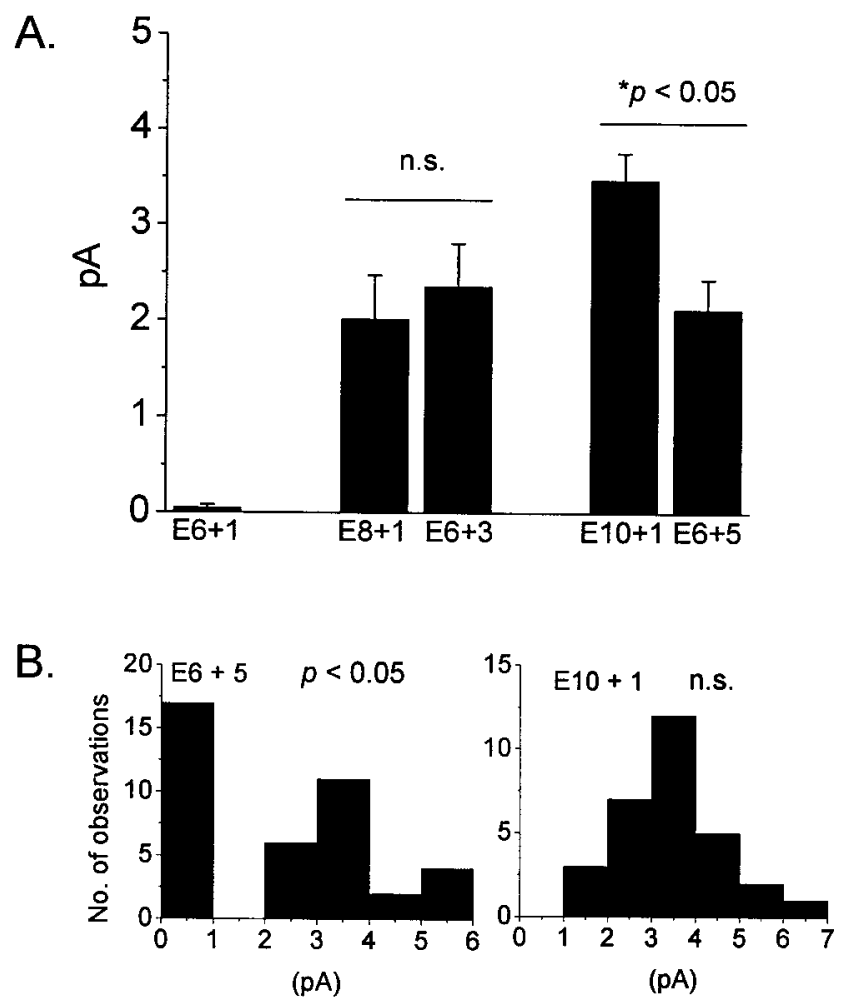

Figure 4. Evidence for epigenetic regulation of cGMP-gated channel expression in developing cones. $A$, Summary of mean currents evoked by bath application of $100 \mu \mathrm{M}$ cGMP to inside-out patches excised from cells isolated at E6, E8, or E10 and then maintained in culture in the dark for various periods of time after dissociation. Cells isolated at E6 did not express channels $1 \mathrm{~d}$ after isolation $(\mathrm{E} 6+1)$ but expressed an intermediate level of channels $3 \mathrm{~d}(\mathrm{E} 6+3)$ or $5 \mathrm{~d}(\mathrm{E} 6+5)$ after isolation. Channel expression in E6 +3 is similar to that observed in age-matched $\mathrm{E} 8+1$ cells. In contrast, channel expression in E6 +5 cells is significantly $(p<0.05)$ less than that observed in age-matched E10 +1 cells, indicating the need for a factor not present in these culture conditions. $B$, Distribution of response amplitudes in E6 +5 cells and E10 +1 cells from data shown in $A$. Note significantly $(p<0.05)$ non-normal and apparently bimodal distribution of response amplitudes in E6 +5 cells and normal distribution of response amplitudes in E10 + 1 cells, suggesting that populations of cells differ in their ability to express functional channels in these culture conditions.

reversible translational inhibitor anisomycin $(0.1 \mathrm{mg} / \mathrm{ml})$, or in the absence of medium supplements (Fig. 6A). We observed that anisomycin not only blocked the stimulatory effect of CEE, it caused an almost complete loss of cGMP-gated channels in all cells. A similar effect was observed in photoreceptors treated with brefeldin-A (1 $\mu \mathrm{g} / \mathrm{ml})$, a drug that causes disruption of the Golgi apparatus and thereby blocks targeting and translocation of plasma membrane proteins (Fig. 6A). These inhibitors resulted in a lower density of cells in the cultures, but those that were present appeared healthy by electrophysiological criteria. Together, these results indicate that cGMP-gated cationic channels have a high turnover rate in cone photoreceptors at this stage of development and suggest that the mean plasma membrane channel density reflects a balance between biosynthesis-plasma membrane insertion and degradation. These data are consistent with the hypothesis that the trophic effects of CEE are associated with synthesis of new channel molecules, although they do not rule out trophic effects on degradation of channel molecules. A number of different cytokines and growth factors evoke changes in gene expression through transduction cascades that include the mitogen-
A.

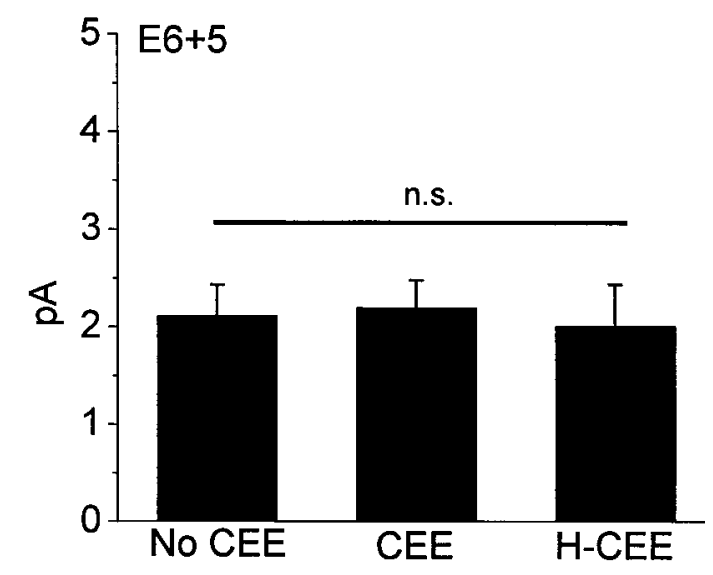

B.

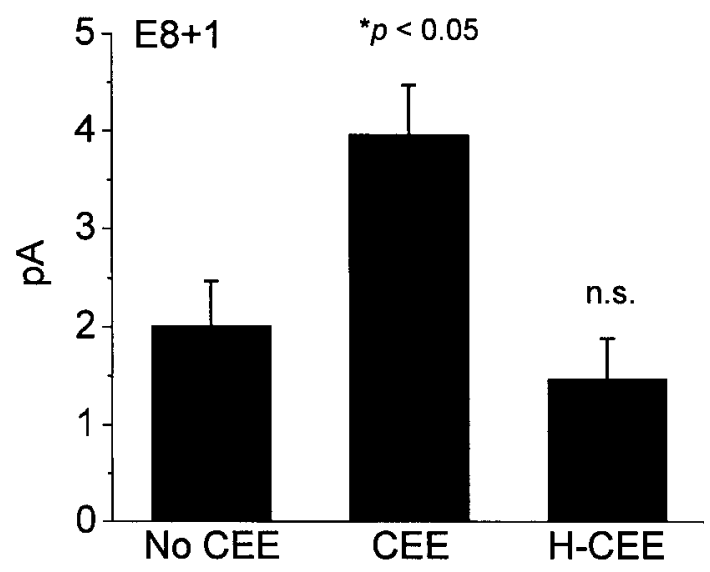

Figure 5. Chick embryo extracts (CEE) stimulate functional expression of cGMP-gated channels in cones developing in vitro. The effects of CEE depend on the stage at which cells are removed from the retinal microenvironment. $A, \mathrm{E} 6+5$ cells were cultured for all $5 \mathrm{~d}$ in the presence of basal medium (no CEE), in medium containing 10\% CEE, or in $10 \%$ heat-inactivated CEE ( $H$-CEE). None of these treatments had a significant effect on the expression of functional channels in cones isolated at E6. B, Application of $10 \% \mathrm{CEE}$ to E8 +1 cells for $12 \mathrm{hr}$ caused a robust stimulation of channel expression, whereas heat-inactivated CEE $(H-$ $C E E$ ) had no effect.

activated protein kinase Erk (for review, see Derkinderen et al., 1999) and the lipid kinase phosphoinositide-3-kinase (PI3-K). $\mathrm{PI} 3-\mathrm{K}$ is of special interest because of its involvement in insertion and translocation of membrane proteins (for review, see Fruman et al., 1998; Anderson et al., 1999). Therefore, we have examined whether inhibitors of these signaling pathways block the stimulatory effects of CEE. To test for Erk involvement, we pretreated cells with PD90859, a selective inhibitor of MEK1 (Alessi et al., 1995; Dudley et al., 1995), an enzyme required for Erk activation in most signaling pathways (Matsuda et al., 1992; Seger et al., 1992). Treatment with $50 \mu \mathrm{M}$ PD98059 throughout the period of CEE application prevented the increases in cGMP-gated channels normally evoked by CEE (Fig. 6B). A similar effect was produced by LY294002 (50 $\mu \mathrm{M})$, a selective inhibitor of PI3-K (Vlahos et al., 1994; Brunn et al., 1996) (Fig. 6B). Neither of these drugs altered the behavior of channels that were already in the membrane, and in contrast to anisomycin and brefeldin-A, did not cause a decrease in basal levels of channels. These data 
A.

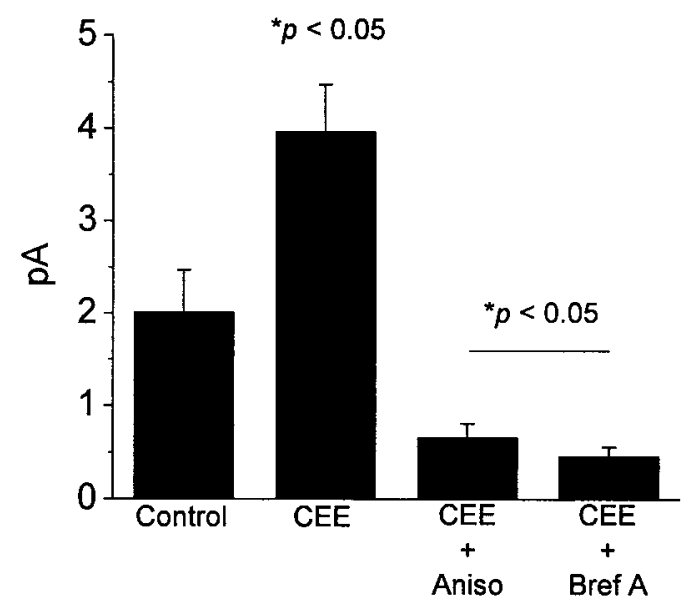

B.

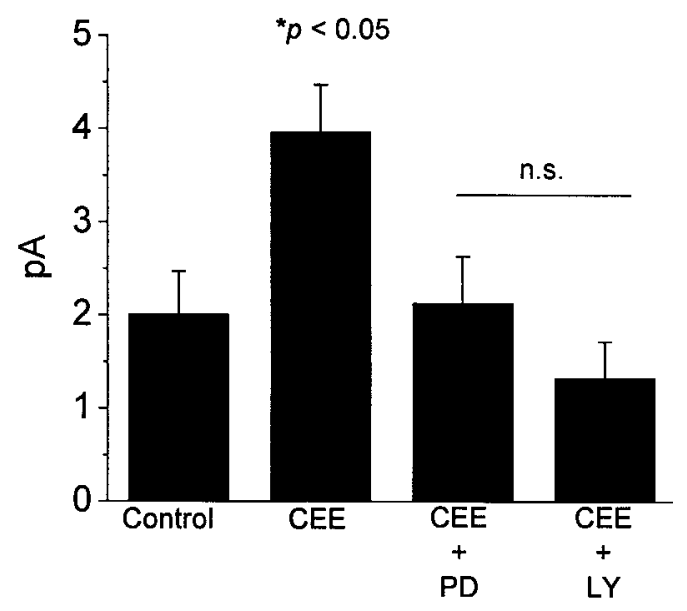

Figure 6. Effects of protein synthesis inhibitors and kinase inhibitors on channel-stimulatory effects of chick embryo extract (CEE) in developing chick cones. All experiments were performed on E8 +1 cells. A, Application of CEE for $12 \mathrm{hr}$ caused a robust stimulation of functional channel expression compared with control cells cultured in basal media. Channel expression was markedly reduced when CEE was applied in the presence of either the translational inhibitor anisomycin $(0.1 \mathrm{mg} / \mathrm{ml})$ or brefeldin A $(1 \mu \mathrm{g} / \mathrm{ml})$, an agent that causes disruption of the Golgi apparatus. Mean current amplitudes in anisomycin- or brefeldin A-treated cells were significantly lower than those observed in either control or CEE-treated cells, suggesting that functional plasma membrane channels turn over rapidly. $B$, The stimulatory effects of CEE are completely blocked by PD98059 $(50 \mu \mathrm{M})$, an inhibitor of Erk MAP kinase, or LY294002 $(50 \mu \mathrm{M})$, an inhibitor of PI3 kinase. Current amplitudes in drug-treated cells are not significantly different from controls cultured in the absence of CEE. These drugs do not produce direct blockade of the channels.

suggest that the stimulatory effects of CEE on functional expression of cGMP-gated channels are attributable in part to well known signal transduction cascades.

Given that CEE causes stimulation of cGMP-gated channel expression in cone photoreceptors at E8 or later, we have also examined the effects of several recombinant trophic factors chosen because they have been shown by others to play some role in retinal differentiation and development or in regulation of ion channel expression in other systems. CNTF was of special interest, because the receptors for this growth factor are not detectable in the chick retina until E8 (Fuhrmann et al., 1998b) and because
Table 1. Effects of recombinant trophic factors on expression of cGMPgated cationic channels in embryonic cones

\begin{tabular}{ll}
$\begin{array}{l}\text { Trophic factors, concentration, } \\
\text { and number of observations }\end{array}$ & $\begin{array}{l}\text { Response amplitude } \\
\text { compared to controls }\end{array}$ \\
\hline CNTF $(20 \mathrm{ng} / \mathrm{ml}) ; n=27$ & $\mathrm{NS}^{a}$ \\
BDNF $(25 \mathrm{ng} / \mathrm{ml}) ; n=13$ & $\mathrm{NS}$ \\
BDNF $(100 \mathrm{ng} / \mathrm{ml}) ; n=11$ & $\mathrm{NS}$ \\
bFGF $(20 \mathrm{ng} / \mathrm{ml}) ; n=15$ & $\mathrm{NS}$ \\
GDNF $(10 \mathrm{ng} / \mathrm{ml}) ; n=25$ & $\mathrm{NS}$ \\
IGF-1 $(20 \mathrm{ng} / \mathrm{ml}) ; n=12$ & $\mathrm{NS}$ \\
$\beta$-neuregulin- $1(10 \mathrm{nM}) ; n=9$ & $\mathrm{NS}$ \\
TGF $\beta 1(1 \mathrm{nM}) n=18$ & $\mathrm{NS}$
\end{tabular}

$\overline{\text { Inside-out patch recordings were made from dissociated E8 chick cones treated with }}$ recombinant trophic factors at the indicated concentrations for $12 \mathrm{hr}$. Responses were evoked by bath application of $100 \mu \mathrm{M}$ cGMP. Growth factors tested included ciliary neurotrophic factor (CNTF), brain-derived neurotrophic factor (BDNF), basic fibroblast growth factor (bFGF), glial cell line-derived neurotrophic factor (GDNF), insulin-like growth factor-1 (IGF-1), and transforming growth factor- $\beta 1$. None of these factors produced a statistically significant stimulation of mean response amplitudes compared to controls cultured in the absence of recombinant factors (denoted by NS).

${ }^{a}$ In this experiment, CNTF-treated cells were compared to control cells cultured in the absence of CNTF.

application of this factor tends to promote acquisition of other cone phenotypes in chick retinal cells (Fuhrmann et al., 1995). However, none of the factors tested, including CNTF, caused significant stimulation of cGMP-gated cationic channels in E8 photoreceptors (Table 1). (The controls for the CNTF experiments consisted of culture media lacking this factor). These data suggest that some other factor is responsible for the trophic effects of CEE, or alternatively, that simultaneous application of multiple trophic factors is required to obtain functional stimulation of cGMP-gated channels.

\section{DISCUSSION}

The cyclic GMP-gated cationic channels of vertebrate photoreceptors are essential for visual phototransduction. In this study, we have examined the developmental regulation of the cone form of these ion channels in the cone-rich chick retina. We have shown that expression of cone-type cGMP-gated channel mRNA in embryonic chick precedes expression of functional plasma membrane channels. Channels in the membrane appear to turn over at a high rate, at least at this stage of development. Moreover, the data presented here, taken together with previous studies (Cook et al., 1998), are consistent with the existence of at least two different subpopulations of cones, which begin to express functional channels at different developmental stages. Finally, expression of functional cGMP-gated channels in a cone subpopulation appears to require one or more soluble differentiation factors that are presumably present in the normal microenvironment of the developing retina. Trophic regulation of cyclic nucleotide-gated channel expression has not been reported previously in any species or cell type.

Chickens express several morphologically distinct classes of cones, including at least three types of single cones and two types of double cones (Morris and Shorey, 1967; Morris, 1970, 1973). Chick retinal cells leave the cell cycle between E4 and E8 (Fujita and Horii, 1963; Kahn, 1974). Different morphological classes of cones are initially formed at somewhat different developmental stages, although there is substantial overlap in their birth dates (Morris, 1973), and it is clear that individual precursor cells can give rise to multiple retinal cell types (Cepko, 1993; Belecky- 
Adams et al., 1996). More recent studies of photoreceptor cytogenesis in chick retina using "window-labeling" methods suggest that essentially all photoreceptors leave the cell cycle by E6 during normal in ovo development (Belecky-Adams et al., 1996). At E6, we detected few if any functional cGMP-gated channels in cells with containing oil droplets. Close to half of patches from morphologically identifiable cones contained substantial numbers of these channels by E8, and essentially all cells with cone morphology express these channels by E10. Therefore, these data provide additional evidence that cones undergo a period of functional differentiation after they leave the cell cycle, and that the length of time required for functional differentiation is not uniform in all photoreceptors.

This observation is reminiscent of the regulation of cone opsin expression in the developing chick retina, in which longwavelength (red and green) opsin transcripts are initially detectable at E14 in the central retina, whereas short-wavelength (blue and violet) opsin transcripts are initially detectable 2 d later (Bruhn and Cepko, 1996). One caveat of the cone opsin study is that transcript expression was measured by nonradioactive in situ hybridization, which may not have had sufficient sensitivity to detect low but functionally significant expression of these transcripts. Nevertheless, those data provided the initial evidence that different types of cones differentiate at different rates. It is possible that the bimodal distributions of channel expression observed at E8 reflect subpopulations of cells fated to differentiate into different types of cones. Unfortunately, it is not possible to distinguish different types of cones in dissociated cell culture because the outer segments are rudimentary, and the oil droplets lack detectable pigments. These morphological features do not change significantly even after long periods in cell culture.

A key observation of the present study is that the functional expression of cGMP-gated channels requires trophic support. Thus, at least a subpopulation of cones that develop in cell culture fail to express cGMP-gated channels at anything like normal levels. Application of chick embryo extract, a rich source of trophic factors, allows essentially all cones to express functional channels, provided that they are placed in culture at E8. One explanation for the latter observation is that exposure to the retinal microenvironment is required for some photoreceptor cells to respond to trophic factors, possibly because expression of receptors for one or more of the essential factors is regulated by inductive interactions (see further below). Compared with other neuronal phenotypes, relatively little is known about the factors that regulate the developmental expression of ionic channels. The available studies indicate that different modes of developmental regulation of channels can exist, even within a single cell type. For example, developmental changes in the action potential waveform in Xenopus spinal neurons and striated myocytes are essentially identical in cells that develop in vivo or in single-cell cultures (Henderson and Spitzer, 1986). Consistent with this, expression of several classes of ionic currents in these cells, including delayed rectifier and transient $\mathrm{K}^{+}$currents (Desarmenien et al., 1993) proceeds according to a cell-intrinsic program. Similar results have been obtained for $\mathrm{Na}^{+}, \mathrm{Ca}^{2+}$, and delayed rectifier $\mathrm{K}^{+}$ currents in developing chick parasympathetic neurons (Dourado and Dryer, 1992). In contrast, expression of other ionic channels in chick parasympathetic neurons (e.g., A-type $\mathrm{K}^{+}$channels and $\mathrm{Ca}^{2+}$-activated $\mathrm{K}^{+}$channels) is regulated by inductive cell-cell interactions (Dourado et al., 1994) mediated by soluble neurotrophic factors (Subramony et al., 1996; Cameron et al., 1998, 1999; Lhuillier and Dryer, 2000). A similar situation may pertain in chick photoreceptors. Thus, Gleason et al. (1992) observed that essentially all chick cones express L-type $\mathrm{Ca}^{2+}$ channels by the developmental stage at which these cells form ribbon synapses with second-order neurons, even when they develop in dissociated cell culture. In contrast, expression of cGMP-gated channels in at least some cones requires an epigenetic factor that is not present in the dissociated cell culture environment but that is present in chick embryo extract. Indeed, the data in the present study cannot rule out the possibility that expression of these channels in all cones requires inductive interactions, which occur in some chick cones before E6.

An initially surprising result of the present study was that inhibition of protein synthesis (using anisomycin) or disruption of the Golgi apparatus (using brefeldin-A) caused a marked fall in functional cGMP-gated channels within $12 \mathrm{hr}$. This occurred even in the presence of chick embryo extracts. Moreover, acute application of these drugs did not cause direct pore blockade of channels that were already in the plasma membrane. These data indicate that cone cGMP-gated channels in the plasma membrane turn over at a high rate at this stage of development. This may reflect continuous membrane turnover characteristic of vertebrate photoreceptor outer segments (Young, 1967; Anderson et al., 1978) including rods and cones of chicks (Young, 1976), but it may also be a more general feature of at least some types of ionic channels. Although rates of ion channel turnover have not been studied in many cell types, there is precedent for this type of observation. For example, turnover of various $\mathrm{K}^{+}$channels (Levitan and Takimoto, 1998) and N-type $\mathrm{Ca}^{2+}$ channels (Passafaro et al., 1992; Sher et al., 1998) can occur at similar rates and may provide a dynamic mechanism for fine tuning of channel expression (Passafaro et al., 1994). In this regard, the outer segments of cultured embryonic chick photoreceptors are quite rudimentary, and there is no evidence to date for rapid membrane turnover in other parts of the photoreceptor cell.

To date, we have not identified the active channel stimulatory factor present in chick embryo extracts or a single recombinant trophic factor that can mimic the effect of chick embryo extract. Although a number of plausible candidates were tested, there are certainly additional trophic factors that are likely to be present in the retina. However, it is also possible that stimulation of these channels requires the integrated action of more than one trophic factor. There is precedent for this, because regulation of the expression $\mathrm{Ca}^{2+}$-activated $\mathrm{K}^{+}$channels in developing chick parasympathetic neurons is regulated by multiple trophic factors that have synergistic and antagonistic actions (Dourado et al., 1994; Cameron et al., 1998, 1999). In this regard, it bears noting that receptors for CNTF are not expressed in chick retinal photoreceptors until E8 (Fuhrmann et al., 1998a,b), which is also the stage at which photoreceptors acquire the ability to respond to chick embryo extracts. Therefore, although CNTF alone does not mimic the channel stimulatory effects of embryo extract, we cannot yet exclude a role for this factor in regulating acquisition of mature electrophysiological properties of cones. The present study also indicates that channel stimulation chick embryo extracts requires activation of an Erk form of mitogen-activated protein kinase and phosphoinosite-3-kinase. Both signaling cascades are used by many different growth factors. Nevertheless, this observation may eventually provide a clue to elucidate cellular mechanisms underlying the regulation of these ionic channels.

In summary, we have described the development of functional cGMP-gated channels in cones of the embryonic chick. These 
channels are expressed early in the embryonic development of the chick, and their expression in at least some cells appears to require epigenetic control mechanisms most likely mediated by trophic factors present in the microenvironment of the developing retina.

\section{REFERENCES}

Adler R (1986) Developmental predetermination of the structural and molecular polarization of photoreceptor cells. Dev Biol 117:520-527.

Adler R (1993) Determination of cellular types in the retina. Invest Ophthalmol Vis Sci 34:1677-1682.

Adler R, Hatlee M (1989) Plasticity and differentiation of embryonic retinal cells after terminal mitosis. Science 243:391-393.

Adler R, Lindsey JD, Elsner CL (1984) Expression of cone-like properties by chick embryo neural retina cells in glial-free monolayer cultures. J Cell Biol 99:1173-1178.

Ahmad I, Redmond LJ, Barnstable CJ (1990) Developmental and tissue-specific expression of the rod photoreceptor cGMP-gated ion channel gene. Biochem Biophys Res Commun 173:463-470.

Alessi DR, Cuenda A, Cohen P, Dudley DT, Saltiel AR (1995) PD098059 is a specific inhibitor of the activation of mitogen-activated protein kinase kinase in vitro and in vivo. J Biol Chem 270:27489-27494.

Anderson DH, Fisher SK, Steinberg RH (1978) Mammalian cones: disc shedding, phagocytosis, and renewal. Invest Ophthalmol Vis Sci 17:117-133.

Anderson RA, Boronenkov IV, Doughman SD, Kunz J, Loijens JC (1999) Phosphatidylinositol phosphate kinases, a multifaceted family of signaling enzymes. J Biol Chem 274:9907-9910.

Belecky-Adams T, Cook B, Adler R (1996) Correlations between terminal mitosis and differentiated fate of retinal precursor cells in vivo and in vitro: analysis with the window-labeling technique. Dev Biol 178:304-315.

Blanks JC, Johnson LV (1984) Specific binding of peanut lectin to a class of retinal photoreceptor cells: a species comparison. Invest Ophthalmol Vis Sci 25:546-557.

Bonigk W, Altenhofen W, Muller F, Dose A, Illing M, Molday RS, Kaupp UB (1993) Rod and cone photoreceptor cells express distinct genes for cGMP-gated channels. Neuron 10:865-877.

Bruhn SL, Cepko CL (1996) Development of the pattern of photoreceptors in the chick retina. J Neurosci 16:1430-1439.

Brunn G, Williams J, Sabers C, Wiederrecht G, Lawrence J, Abraham R (1996) Direct inhibition of the signaling functions of the mammalian target of rapamycin by the phosphoinositide 3-kinase inhibitors, wortmannin and LY294002. EMBO J 15:5256-5267.

Cameron JS, Lhuillier L, Subramony P, Dryer SE (1998) Developmental regulation of neuronal $\mathrm{K}^{+}$channels by target-derived TGF beta in vivo and in vitro. Neuron 21:1045-1053.

Cameron JS, Dryer L, Dryer SE (1999) Regulation of neuronal K ${ }^{+}$ currents by target-derived factors: opposing actions of two different isoforms of TGF $\beta$. Development 126:4157-4164.

Cepko C (1993) Lineage versus environment in the embryonic retina. Trends Neurosci 16:96-97.

Chiang RK, Barnstable CJ (1998) Developmental expression of the rat rod photoreceptor cGMP-gated cation channel. Vis Neurosci 15:823-829.

Cook B, Portera-Cailliau C, Adler R (1998) Developmental neuronal death is not a universal phenomenon among cell types in the chick embryo retina. J Comp Neurol 396:12-19.

Das I, Hempstead B, Macleish P, Sparrow J (1997) Immunohistochemical analysis of the neurotrophins BDNF and NT-3 and their receptors trk $\mathrm{B}$, trk $\mathrm{C}$, and $\mathrm{p} 75$ in the developing chick retina. Vis Neurosci 14:835-842.

Derkinderen P, Enslen H, Girault J (1999) The Erk/MAP-kinases cascade in the nervous system. NeuroReport 10:R24-R34.

Desarmenien MG, Clendening B, Spitzer NC (1993) In vivo development of voltage-dependent ionic currents in embryonic Xenopus spinal neurons. J Neurosci 13:2575-2581.

Diaz B, Serna J, De Pablo F, de la Rosa EJ (2000) In vivo regulation of cell death by embryonic (pro)insulin and the insulin receptor during early retinal neurogenesis. Development 127:1641-1649.

Dourado MM, Dryer SE (1992) Changes in the electrical properties of chick ciliary ganglion neurones during embryonic development. J Physiol (Lond) 449:411-428.

Dourado MM, Brumwell C, Wisgirda ME, Jacob MH, Dryer SE (1994) Target tissues and innervation regulate the characteristics of $\mathrm{K}^{+}$currents in chick ciliary ganglion neurons developing in situ. J Neurosci 14:3156-3165.

Dryer SE, Henderson D (1991) A cyclic GMP-activated channel in dissociated cells of the chick pineal gland. Nature 353:756-758.

Dryer SE, Henderson D (1993) Cyclic GMP-activated channels of the chick pineal gland: effects of divalent cations, $\mathrm{pH}$, and cyclic AMP. J Comp Physiol [A] 172:271-279.

Dryja TP, Finn JT, Peng YW, McGee TL, Berson EL, Yau KW (1995) Mutations in the gene encoding the alpha subunit of the rod cGMPgated channel in autosomal recessive retinitis pigmentosa. Proc Natl Acad Sci USA 92:10177-10181.

Dudley DT, Pang L, Decker SJ, Bridges AJ, Saltiel AR (1995) A synthetic inhibitor of the mitogen-activated protein kinase cascade. Proc Natl Acad Sci USA 92:7686-7689.

Dzeja C, Hagen V, Kaupp UB, Frings S (1999) $\mathrm{Ca}^{2+}$ permeation in cyclic nucleotide-gated channels. EMBO J 18:131-144.

Frade J, Bovolenta L, Martinez-Morales J, Arribas A, Barbas J, Rodriguez-Tébar A (1997) Control of early cell death by BDNF in the chick retina. Development 124:3313-3320.

Fruman D, Meyers R, Cantley L (1998) Phosphoinositide kinases. Annu Rev Biochem 67:481-507.

Fuhrmann S, Kirsch M, Hofmann HD (1995) Ciliary neurotrophic factor promotes chick photoreceptor development in vitro. Development 121:2695-2706.

Fuhrmann S, Heller S, Rohrer H, Hofmann HD (1998a) A transient role for ciliary neurotrophic factor in chick photoreceptor development. J Neurobiol 37:672-683.

Fuhrmann S, Kirsch M, Heller S, Rohrer H, Hofmann HD (1998b) Differential regulation of ciliary neurotrophic factor receptor-a expression in all major neuronal cell classes during development of the chick retina. J Comp Neurol 400:244-254.

Fujita S, Horii M (1963) Analysis of cytogenesis in chick retina by tritiated thymidine autoradiography. Arch Histol Jpn 23:359-366.

Gleason E, Mobbs P, Nuccitelli R, Wilson M (1992) Development of functional calcium channels in cultured avian photoreceptors. Vis Neurosci 8:315-327.

Gordon SE, Brautigan DL, Zimmerman AL (1992) Protein phosphatases modulate the apparent agonist affinity of the light-regulated ion channel in retinal rods. Neuron 9:739-748.

Goulding E, Tibbs G, Liu D, Siegelbaum S (1993) Role of H5 domain in determining pore diameter and ion permeation through cyclic nucleotide-gated channels. Nature 364:61-64.

Grunwald ME, Yu WP, Yu HH, Yau KW (1998) Identification of a domain on the beta-subunit of the rod cGMP-gated cation channel that mediates inhibition by calcium-calmodulin. J Biol Chem 273:9148-9157.

He L, Campbell ML, Srivastava D, Blocker YS, Harris JR, Swaroop A, Fox DA (1998) Spatial and temporal expression of AP-1 responsive rod photoreceptor genes and bZIP transcription factors during development of the rat retina. Mol Vis 4:32.

Henderson LP, Spitzer NC (1986) Autonomous early differentiation of neurons and muscle cells in single cell cultures. Dev Biol 113:381-387.

Hicks D, Courtois Y (1992) Fibroblast growth factor stimulates photoreceptor differentiation in vitro. J Neurosci 12:2022-2033.

Hsu YT, Molday RS (1993) Modulation of the cGMP-gated channel of rod photoreceptor cells by calmodulin. Nature 361:76-79.

Kahn AJ (1974) An autoradiographic analysis of the time of appearance of neurons in the developing chick neural retina. Dev Biol 38:30-40.

LeConte L, Barnstable CJ (2000) Impairment of rod cGMP-gated channel alpha-subunit expression leads to photoreceptor and bipolar cell degeneration. Invest Ophthalmol Vis Sci 41:917-926.

Levitan ES, Takimoto K (1998) Dynamic regulation of $\mathrm{K}^{+}$channel gene expression in differentiated cells. J Neurobiol 37:60-68.

Lhuillier L, Dryer SE (2000) Developmental regulation of neuronal $\mathrm{K}_{\mathrm{Ca}}$ channels by TGF $\beta 1$ : transcriptional and posttranscriptional effects mediated by Erk MAP-kinase. J Neurosci 20:5612-5622.

Lillien L, Cepko C (1992) Control of proliferation in the retina: temporal changes in responsiveness to FGF and TGF $\alpha$. Development $115: 253-266$

Liu D, Tibbs G, Siegelbaum S (1996) Subunit stoichiometry of cyclic nucleotide-gated channels and effects of subunit order on channel function. Neuron 16:983-990.

Liu D, Tibbs G, Paoletti P, Siegelbaum S (1998) Constraining ligandbinding site stoichiometry suggests that a cyclic nucleotide-gated channel is composed of two functional dimers. Neuron 21:235-248.

Matsuda S, Kosako H, Takenaka K, Moriyama K, Sakai H, Akiyama T, Gotoh Y, Nishida E (1992) Xenopus MAP kinase activator: identification and function of a key intermediate in the phosphorylation cascade. EMBO J 11:973-982.

Matulef K, Flynn G, Zagotta W (1999) Molecular rearrangements in the ligand-binding domain of cyclic nucleotide-gated channels. Neuron 24:443-452.

Molday R, Molday L (1998) Molecular properties of the cGMP-gated channel of rod photoreceptors. Vision Res 38:1315-1323.

Molokanova E, Trivedi B, Savchenko A, Kramer RH (1997) Modulation of rod photoreceptor cyclic nucleotide-gated channels by tyrosine phosphorylation. J Neurosci 17:9068-9076.

Molokanova E, Savchenko A, Kramer R (1999a) Noncatalytic inhibition of cyclic nucleotide-gated channels by tyrosine kinase induced by genistein. J Gen Physiol 113:45-56. 
Molokanova E, Maddox F, Luetje CW, Kramer RH (1999b) Activitydependent modulation of rod photoreceptor cyclic nucleotide-gated channels mediated by phosphorylation of a specific tyrosine residue. J Neurosci 19:4786-4795.

Molokanova E, Savchenko A, Kramer RH (2000) Interactions of cyclic nucleotide-gated channel subunits and protein tyrosine kinase probed with genistein. J Gen Physiol 115:685-696.

Morris VB (1970) Symmetry in a receptor mosaic demonstrated in the chick from the frequencies, spacing and arrangement of the types of retinal receptor. J Comp Neurol 140:359-398.

Morris VB (1973) Time differences in the formation of the receptor types in the developing chick retina. J Comp Neurol 151:323-330.

Morris VB, Shorey CD (1967) An electron microscope study of types of receptor in the chick retina. J Comp Neurol 129:313-340.

Ni M, Yamaki K, Kikuchi T, Ferrick M, Shinohara T, Nussenblatt RB, Chan CC (1992) Developmental expression of S-antigen in fetal human and rat eye. Curr Eye Res 11:219-229.

Paoletti P, Young E, Siegelbaum S (1999) C-Linker of cyclic nucleotidegated channels controls coupling of ligand binding to channel gating. J Gen Physiol 113:17-34.

Passafaro M, Clementi F, Sher E (1992) Metabolism of omegaconotoxin-sensitive voltage-operated calcium channels in human neuroblastoma cells: modulation by cell differentiation and anti-channel antibodies. J Neurosci 12:3372-3379.

Passafaro M, Clementi F, Pollo A, Carbone E, Sher E (1994) OmegaConotoxin and $\mathrm{Cd}^{2+}$ stimulate the recruitment to the plasma membrane of an intracellular pool of voltage-operated $\mathrm{Ca}^{2+}$ channels. Neuron 12:317-326.

Repka A, Adler R (1992) Differentiation of retinal precursor cells born in vitro. Dev Biol 153:242-249.

Root MJ, MacKinnon R (1993) Identification of an external divalent cation-binding site in the pore of a cGMP-activated channel. Neuron 11:459-466.

Root MJ, MacKinnon R (1994) Two identical noninteracting sites in an ion channel revealed by proton transfer. Science 265:1852-1856.

Ruiz M, Karpen J (1997) Single cyclic nucleotide-gated channels locked in different ligand-bound states. Nature 389:389-392.
Seger R, Ahn NG, Posada J, Munar ES, Jensen AM, Cooper JA, Cobb MH, Krebs EG (1992) Purification and characterization of mitogenactivated protein kinase activator(s) from epidermal growth factorstimulated A431 cells. J Biol Chem 267:14373-14381.

Seifert R, Eismann E, Ludwig J, Baumann A, Kaupp UB (1999) Molecular determinants of a $\mathrm{Ca}^{2+}$-binding site in the pore of cyclic nucleotide-gated channels: S5/S6 segments control affinity of intrapore glutamates. EMBO J 18:119-130.

Shammat I, Gordon S (1999) Stoichiometry and arrangement of subunits in rod cyclic nucleotide-gated channels. Neuron 23:809-819.

Sher E, Rosa P, Francolini M, Codignola A, Morlacchi E, Taverna E, Giovannini F, Brioschi A, Clementi F, McEnery MW, Passafaro M (1998) Metabolism and trafficking of N-type voltage-operated calcium channels in neurosecretory cells. J Bioenerg Biomembr 30:399-407.

Siegel S, Castellan NJ (1988) Nonparametric statistics for the behavioral sciences, Ed 2. New York: McGraw-Hill.

Stryer L (1986) Cyclic GMP cascade of vision. Annu Rev Neurosci 9:87-119.

Subramony P, Raucher S, Dryer L, Dryer SE (1996) Posttranslational regulation of $\mathrm{Ca}^{2+}$-activated $\mathrm{K}^{+}$currents by a target-derived factor in developing parasympathetic neurons. Neuron 17:115-124.

Treisman JE, Morabito MA, Barnstable CJ (1988) Opsin expression in the rat retina is developmentally regulated by transcriptional activation. Mol Cell Biol 8:1570-1579.

Vlahos C, Matter W, Hui K, Brown R (1994) A specific inhibitor of phosphatidylinositol 3-kinase, 2-(4-morpholinyl)-8-phenyl-4H-1benzopyran-4-one (LY294002). J Biol Chem 269:5241-5248.

Weitz D, Zoche M, Muller F, Beyermann M, Korschen HG, Kaupp UB, Koch KW (1998) Calmodulin controls the rod photoreceptor CNG channel through an unconventional binding site in the N-terminus of the beta-subunit. EMBO J 17:2273-2284.

Young RW (1967) The renewal of photoreceptor cell outer segments. J Cell Biol 33:61-72.

Young RW (1976) Visual cells and the concept of renewal. Invest Ophthalmol Vis Res 15:700-725. 